\title{
GYROKINETIC SIMULATION OF ISOTOPE SCALING IN TOKAMAK PLASMAS
}

\section{BY}

W.W. LEE AND R.A. SANTORO

\author{
JULY 1995
}
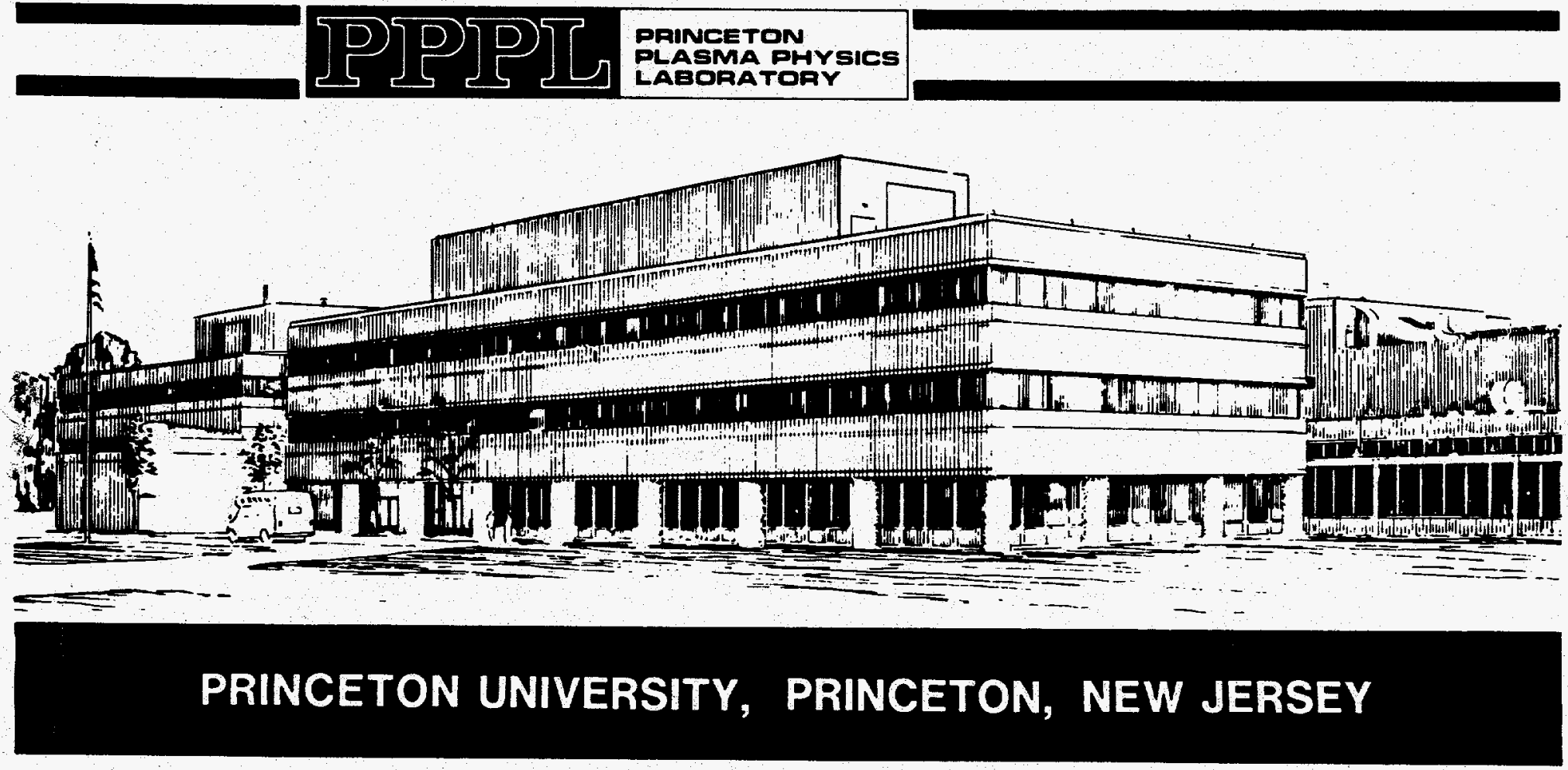


\section{NOTICE}

This report was prepared as an account of work sponsored by an agency of the United States Government. Neither the United States Government nor any agency thereof, nor any of their employees, makes any warranty, express or implied, or assumes any legal liability or responsibility for the accuracy, completeness, or usefulness of any information, apparatus, product, or process disclosed, or represents that its use would not infringe privately owned rights. Reference herein to any specific commercial produce, process, or service by trade name, trademark, manufacturer, or otherwise, does not necessarily constitute or imply its endorsement, recommendation, or favoring by the United States Government or any agency thereof. The views and opinions of authors expressed herein do not necessarily state or reflect those of the United States Government or any agency thereof.

\section{NOTICE}

This report has been reproduced from the best available copy.

Available in paper copy and microfiche.

Number of pages in this report: 19

DOE and DOE contractors can obtain copies of this report from:

Office of Scientific and Technical Information

P.O. Box 62

Oak Ridge, TN 37831 ;

(615) $576-8401$.

This report is publicly available from the:

National Technical Information Service

Department of Commerce

5285 Port Royal Road

Springfield, Virginia 22161

(703) $487-4650$ 


\section{DISCLAIMER}

Portions of this document may be illegible in electronic image products. Images are produced from the best available original document. 


\title{
Gyrokinetic Simulation of Isotope Scaling in Tokamak Plasmas
}

\author{
W. W. Lee \\ Princeton Plasma Physics Laboratory, Princeton University \\ P. O. Box 451, Princeton, NJ 08543 \\ and \\ R. A. Santoro \\ Department of Physics, University of California at Irvine \\ Irvine, CA 92717
}

\begin{abstract}
A three-dimensional global gyrokinetic particle code in toroidal geometry has been used for investigating the transport properties of ion temperature gradient (ITG) drift instabilities in tokamak plasmas. Using the isotopes of hydrogen $\left(H^{+}\right)$, deuterium $\left(D^{+}\right)$and tritium $\left(T^{+}\right)$, we have found that, under otherwise identical conditions, there exists a favorable isotope scaling for the ion thermal diffusivity, i.e., $\chi_{i}$ decreases with mass. Such a scaling, which exists both at the saturation of the instability and also at the nonlinear steady state, can be understood from the resulting wavenumber and frequency spectra.
\end{abstract}


The agreement between the recent beam emission spectroscopy and microwave reflectometry measurements of the density fluctuations for the supershot discharges in TFTR $^{1,2}$ and the $3 \mathrm{D}$ gyrokinetic particle simulation of the ion temperature gradient (ITG) drift instability ${ }^{3}$ have not only shown the importance of microturbulence for tokamak confinement but also pointed out the dominant role assumed by the long wavelength $\left(k_{\perp} \rho_{i}<1\right)$ fluctuations. In this paper, we report on the investigation concerning the effects of these long wavelength modes on transport scaling. More specifically, we have used various hydrogenic isotopes $\left(\mathrm{H}^{+}, \mathrm{D}^{+}\right.$, and $\left.\mathrm{T}^{+}\right)$in the microturbulence simulation to study the trend for mass scaling and, in turn, to obtain some physical insight concerning the mechanisms responsible for anomalous transport.

Briefly, our simulation results give a favorable mass dependence for $\chi_{i}$. Although these simulations have been carried out under most idealized conditions and do not contain all the physics of realistic tokamak discharges, they do contain what we believe to be some of fundamental physics of tokamak plasmas. Therefore, it is not surprising that our mass scaling results are in qualitative agreement with the experimental trend observed in most of the existing tokamaks. ${ }^{4}$ However, the observed mass dependence is not as strong as the latest analyses from the D-T discharges in TFTR. ${ }^{5}$ In the nonlinear steady state of the simulation, two important physical characteristics related to the scaling have been identified: the widths for both the radial wavenumber spectra and the frequency spectra decrease with mass. The significance of these observations will be discussed.

In the simulation, we have used the $\delta f$ scheme for particle pushing, ${ }^{6,7}$ 
for which the original equations of motion for the ion gyrocenters ${ }^{8}$ in the gyrokinetic unit of $\rho_{s}\left(\equiv \sqrt{T_{e} / T_{i}} \rho_{i}\right)$ and $\Omega_{i}\left(\equiv c_{s} / \rho_{s}\right)$ and $c_{s}\left(\equiv \sqrt{T_{e} / m_{i}}\right)$ without the nonlinear parallel acceleration can be written as

$$
\begin{gathered}
\dot{\mathbf{R}} \equiv \frac{d \mathbf{R}}{d t}=U \hat{\mathbf{b}}^{*}+\mu \hat{\mathbf{b}} \times \frac{\partial}{\partial \mathbf{R}} \ln B+\hat{\mathbf{b}} \times \frac{\partial \bar{\phi}}{\partial \mathbf{R}}, \\
\dot{U} \equiv \frac{d U}{d t}=-\hat{\mathbf{b}}^{*} \cdot \mu \frac{\partial}{\partial \mathbf{R}} \ln B,
\end{gathered}
$$

and $\mu / B \equiv v_{\perp}^{2} / 2 B=$ const., where $\hat{\mathbf{b}}^{*}=\hat{\mathbf{b}}+U \hat{\mathbf{b}} \times(\hat{\mathbf{b}} \cdot \partial / \partial \mathbf{R}) \hat{\mathbf{b}}$ and $\bar{\phi}(\mathbf{R})$ is the finite Larmor radius (FLR) modified potential in unit of $e / T_{e}{ }^{9}$ The "weight" of the particle is given by

$$
\dot{w} \equiv \frac{d w}{d t}=-\kappa \frac{\partial \bar{\phi}}{\partial \mathbf{R}} \times \hat{\mathbf{b}} \cdot \hat{\mathbf{r}}-\frac{T_{e}}{T_{i}} U \hat{\mathbf{b}}^{*} \cdot \frac{\partial \bar{\phi}}{\partial \mathbf{R}},
$$

where $\kappa=\kappa_{n}-\left(3 / 2-v^{2} / 2 v_{t}^{2}\right) \kappa_{T}$ and $\hat{\mathbf{r}}$ is the unit vector in the minor radius direction. The corresponding $\delta f$ becomes

$$
\delta f=\sum_{j=1}^{N} w_{j} \delta\left(\mathbf{R}-\mathbf{R}_{j}\right) \delta\left(\mu-\mu_{j}\right) \delta\left(U-U_{j}\right),
$$

where $N$ is the total number of particles in the simulation. Thus, we are solving the equation

$$
(\partial / \partial t+\dot{\mathbf{R}} \cdot \partial / \partial \mathbf{R}+\dot{U} \partial / \partial U) \delta f=\dot{w} f_{M}
$$

in the simulation, where the background Maxwellian $f_{M}$ is spatially homogeneous. With the assumption that the electron response is adiabatic, i.e., $\delta n_{e} / n_{0} \approx \phi(\mathbf{x})$, where $n_{0}$ is the average number density, the gyrokinetic Poisson equation in the Fourier $\mathbf{k}$ space takes the form of

$$
\left[1+\left(T_{e} / T_{i}\right)\left(1-\Gamma_{0}\left(b_{i}\right)\right)\right] \phi(\mathbf{k})=\delta \bar{n}_{i}(\mathbf{k}) / n_{0}
$$


where $\Gamma_{0}=I_{0}\left(b_{i}\right) \exp \left(-b_{i}\right), I_{0}$ is the modified Bessel function and $b_{i} \equiv$ $\left(k_{\perp} \rho_{i}\right)^{2} . \delta \bar{n}_{i}$ is the perturbed number density, $\int \delta f_{i} d U d \mu$, modified by the FLR effects. ${ }^{9}$ The ion thermal diffusivity in the $\delta f$ representation can be written as ${ }^{9}$

$$
\chi_{i}=\frac{1}{\kappa_{T i}+\kappa_{n}} \sum_{j=1}^{N}-\left.\frac{U_{j}^{2}+2 \mu_{j}}{v_{t i}^{2}} w_{j} \frac{\partial \bar{\phi}}{\partial \mathbf{R}}\right|_{\mathbf{R}_{j}} / 3 N
$$

The simulation has been carried out on a $128 \times 128 \times 64$ toroidal grid [a "square" torus model in $\left(x, y,-R_{0} \varphi\right)$ coordinates ${ }^{3}$ ] with $4.2 \times 10^{6}$ ion gyrocenters (or particles). The toroidal and poloidal magnetic fields are given by $B_{t}=B_{0} /\left(1+x / R_{0}\right)$ and $B_{p}=r B_{0} / q R$, respectively, where $q=q_{0}+\left[q_{a}-q_{0}\right](r / a)^{2}$. The ion temperature gradient is represented $\kappa_{T i}=\left(1 / L_{T i 0}\right) \operatorname{sech}^{2}\left(r-r_{0} / L_{w}\right)$, where the maximum is located at $r_{0}$ and $L_{w}$ is the width of the region with active drive. In the gyrokinetic units of $\rho_{s D}$ and $\Omega_{D}^{-1}$ (i.e., $\rho_{s}$ and $\Omega_{i}^{-1}$ for the deuterium ions), the other relevant simulation parameters are: $a=100, R_{0}=1000, q_{0}=1, q_{a}=3, L_{w}=30$, $r_{0}=55, T_{e} / T_{i}=1, L_{n}($ density scale length $) \equiv 1 / \kappa_{n}=\infty$, and $L_{T i 0}=100$, $\Delta t=30$ and $t_{\text {tot }}=150000$.

The time history of the ITG instability in terms of the gyrokinetic electrostatic field energy, ${ }^{9} \sum_{k}\left[1-\Gamma_{0}\left(b_{i}\right)\right]\left(T_{e} / T_{i}\right)\left|e \phi / T_{e}\right|^{2}$, for all three ion species is shown in Fig. 1(a). It clearly shows four different stages of the evolution: linear growth, nonlinear saturation, transition period and steady state. In the linear stage, the trend for the mass dependence of growth rates is consistent with the prediction of $\gamma_{L} \sim 1 / \sqrt{M}$ by Dong et al. ${ }^{10}$ The nonlinear saturation level in Fig. 1(a) seems to track the linear growth and, in turn, has similar mass dependence. After a period of transition, in which the mass 
dependence is reversed, the original trend is again restored in the steady state, where the fluctuating field energy stays roughly constant. Figure 1(b) gives the measured ion thermal diffusivity for all three ion species. It has a mass dependence similar to that of the field energy. In this paper, we will focus on the scaling trend at saturation and at steady state.

To understand the physics for the observed isotope scaling, let us first study the radial wavenumber spectra taken at the linear stage just before the saturation as shown in Fig. $2(\mathrm{a})$. The dominant modes are $m \approx 16,13,11$ for $\mathrm{H}^{+}, \mathrm{D}^{+}$, and $\mathrm{T}^{+}$, respectively, and are characterized by their ballooning structures. ${ }^{3}$ This is the period where $k_{r}$ is at its minimum. Using the full width half maximum (FWHM) as the reference point, one can see the $k_{r} \sim 1 / M^{1 / 4}$ dependence for the three species. This is in agreement with the theoretical predictions for the long wavelength toroidal instabilities that the radial structures are prescribed by the equilibrium profile ${ }^{11}$ (i.e., $L_{w}$ in our case) and that, near the maximum gradient, the radial mode widths are proportional to $\rho_{i}^{1 / 2}\left(\sim M^{1 / 4}\right) \cdot{ }^{12,13}$ However, near the time of saturation and shortly afterwards, there is a breakup of these spatially coherent structures and the corresponding FWHM wavenumbers become more than doubled. During the ensuing transition period, large amplitude oscillations in $k_{r}$ take place between these two extremes. In the steady state, the amplitude settles to around $\Delta k_{r} \approx 0.1 \rho_{s D}^{-1}$ for $0 \leq k_{r} \leq 0.5 \rho_{s D}^{-1}$ and the time-averaged radial wavenumber spectra are shown in Fig. 2(b). Here, the mass dependence for the FWHM wavenumber changes to $k_{r} \sim 1 / M^{1 / 2}$ with $k_{r} \rho_{s} \approx 0.3$. In addition to the active modes observed in the linear stage, lower toroidal harmonics of $m \approx 12,9,7$ for $H^{+}, D^{+}, T^{+}$, respectively, have also been 
excited. The corresponding time-averaged $k_{\theta}$ and $k_{\phi}$ spectra are shown in Figs. 3(a) and (b), respectively. Unlike the $k_{r}$ spectra, the poloidal and toroidal wavenumbers don't oscillate much in time in the nonlinear stage. However, all three spectra have the same property, i.e., $k_{r} \rho_{s}, k_{\theta} \rho_{s}(\approx 0.15)$ and $k_{\phi} \rho_{s}\left(\approx 0.6 \times 10^{-2}\right)$ are all nearly invariant for all three species, where $\rho_{s} \sim \sqrt{M}$. Another interesting diagnostic is the frequency spectra in the second half (nonlinear steady state) of the simulation. Figure 4 shows the spatially averaged spectra along the weak field side of the midplane at a fixed toroidal angle for $\mathrm{H}^{+}, \mathrm{D}^{+}$, and $T^{+}$plasmas. The results indicate that the nonlinear frequency decreases with mass and, interestingly, so does the frequency spread, $\Delta \omega$. This important property is vital for the understanding of the observed scaling, which we will discuss.

To fully understand the results presented here, one needs a self-consistent nonlinear theory, which is beyond the scope of the present paper. Short of that, let us compare them with some of the present understanding of turbulent transport, e.g., the mixing length argument which gives the scaling of $\chi_{i} \sim \gamma_{L} / k_{\perp}^{2}$. Since $\omega_{* T i} / \Omega_{i}=k_{\theta} \rho_{s}^{2} / L_{T i}$, one can argue that $\gamma_{L} / \Omega_{i} \approx$ $\rho_{s} / L_{T i} \sim \sqrt{M}$, if $k_{\theta} \rho_{s}$ is invariant. This mass dependence is in agreement with the calculation by Dong et al. ${ }^{10}$ which also shows that most unstable toroidal ITG modes occur at $k_{\theta} \rho_{s} \approx 0.5$. Thus, we obtain the familiar expression of

$$
\chi_{i} \sim \frac{\rho_{s} / L_{T_{i}}}{\left(k_{r} \rho_{s}\right)^{2}} \frac{c T_{e}}{e B}
$$

Here, the use of the radial wavenumber $k_{r}$ for the diffusion can be justified from the quasilinear theory (see, e.g., Ref. 14). This scaling can also be obtained from a set of gyrofluid equations based on a simplified Eq. (5) with 
$\dot{\mathbf{R}} \approx U \hat{\mathbf{b}}^{*} \cdot \hat{\mathbf{y}}+\hat{\mathbf{b}} \times \partial \phi / \partial \mathbf{R}, \dot{U} \approx 0, \dot{w} \approx-\kappa \partial \phi / \partial y-\left(T_{e} / T_{i}\right) U \hat{\mathbf{b}}^{*} \cdot \partial \phi / \partial \mathbf{R}$, $\hat{\mathrm{b}}^{*} \approx \hat{\mathrm{b}}-\left(U / R_{0}\right) \hat{\mathbf{y}}$, and $\kappa \approx \kappa_{n}-\left(1-U^{2} / v_{t i}^{2}\right) \kappa_{T i} / 2$, where $\hat{\mathrm{b}}$ is in the toroidal direction only. By keeping the first three velocity moments of the equation and ignoring the parallel electric field, these equations give the same ConnorTaylor invariance property ${ }^{15}$ as the simple slab equations described in Ref. 14 and Eq. (8) is again a possible solution.

On the other hand, Dupree in a series of papers in the 1960's first proposed the concept of resonance broadening by stating that the wave-particle interaction can be modified by a broadening of the associated resonance denominator $(\omega-\mathbf{k} \cdot \mathbf{v}+i \Delta \omega)^{-1}$ as a result of an incoherent scattering of particle orbits by the waves. This enhanced scattering causes nonlinear saturation of the instability and, in the steady state, also causes anomalous diffusion over the transverse wavelength through ${ }^{16}$

$$
\Delta \omega \sim k_{\perp}^{2} D .
$$

This scattering can be considered as an enhanced viscosity (and can exist even only one single unstable mode is present; see, e.g., Ref. 17). Equation (9) can also be viewed as the nonlinear version of Eq. (8) in which the linear drive of $\rho_{s} / L_{T i}$ is replaced by its nonlinear counterpart, $\Delta \omega / \Omega_{i}$.

Let us first compare the results for $\chi_{i}$ in Fig. 1(b) with Eq.(8). Based on the measured mass dependence of $k_{r} \sim 1 / M^{1 / 4}$ from Fig. 2 (a) in the linear stage, the quasilinear $\chi_{i}$ should be independent of mass at saturation. Instead, the simulation $\chi_{i}$ 's give the ratios of $(1.35,1.75,1.3)$ for $\left(H^{+} / D^{+}, H^{+} / T^{+}, D^{+} / T^{+}\right)$, which seem to have a $1 / \sqrt{M}$ dependence. The implication is that either the linear drive or the radial mode structure is 
modified. The most likely candidate is the latter, which undergoes drastic breakup during this time. More theoretical understanding is needed. In the steady state, the time-averaged ratios for $\chi_{i}$ are $(1.3,1.8,1.4)$ for $\left(H^{+} / D^{+}, H^{+} / T^{+}, D^{+} / T^{+}\right)$, which have similar dependence on mass as the quasilinear $\chi_{i}$ 's. Substituting the results from Fig. 2 (b) of $k_{r} \sim 1 / \sqrt{M}$ (i.e., $k_{r} \rho_{s} \approx$ const.) into Eq. (8), one finds $\chi_{i} \sim \sqrt{M}$, which gives an opposite scaling. One obvious explanation is that, in the steady state, the linear drive becomes meaningless. One should then use Eq. (9) instead, i.e., replacing the linear drive in Eq. (8) by a nonlinear one. Fig. 4 provides just that and indicates that the fluctuations are less coherent in lighter isotopes, i.e., $\Delta \omega / \Omega_{i}$ 's are larger. One possible reason for this is the radial variation of the temperature gradient for such a plasma. The comparison of $\Delta \omega$ in Fig. 4 can be carried out again by using FWHM. Noting that part of $\Delta \omega$ comes from the FFT sampling error, $2 \pi / t_{\text {tot }}$, one can show that $\Delta \omega_{H} / \Delta \omega_{T} \approx 5$ and Eq.(8), with the nonlinear drive, gives $\chi_{i}^{H} / \chi_{i}^{T} \approx 1.7$ which is consistent with the simulation results. The gyrokinetic electrostatic field energy shown in Fig. 1(a) also has the same trend in its dependence on mass as the thermal diffusivity.

In this paper, we have pointed out the origin of favorable isotope scaling in our simulation and demonstrated the inadequacy of the mixing length argument based on the linear drive to predict such a scaling. Moreover, we have presented the first evidence linking resonance broadening and anomalous transport in tokamak plasmas through the 3D toroidal ITG instability. Hopefully, this work helps to underscore the importance of understanding transport phenomena in tokamaks from the first principles of physics. 
The authors would like to thank Drs. S. E. Parker and J. C. Cummings for discussions and assistance in the GET3D code. Interactions with Drs. T. S. Hahm and L. Chen are also gratefully acknowledged. The present work is supported by the U.S. Department of Energy under Contract No. DEAC02-76-CHO3037 and Grant No. DE-FG03-94ER54271. The Cray C90 at the National Energy Research Supercomputer Center has been used for the simulation. 


\section{References}

${ }^{1}$ R. J. Fonck et al., Phys. Rev. Lett. 70, 3736 (1993).

${ }^{2}$ E. Mazzucato and R. Nazikian, Phys. Rev. Lett. 71, 1840 (1993).

${ }^{3}$ S. E. Parker, W. W. Lee, and R. A. Santoro, Phys. Rev. Lett. 71, 2042 (1993).

${ }^{4}$ M. Bessenrodt-Weberpals, F. Wagner and ASDEX Team, Nuclear Fusion 33, 1205 (1993).

${ }^{5}$ R. J. Hawryluk et al., Phys. Rev. Lett. 72, 3530 (1994).

${ }^{6}$ A. M. Dimits and W. W. Lee, J. Comput. Phys. 107, 309 (1993).

${ }^{7}$ S. E. Parker and W. W. Lee, Phys. Fluids B 5, 77 (1993).

${ }^{8}$ T. S. Hahm, Phys. Fluids 31, 2670 (1988).

${ }^{9}$ W. W. Lee, J. Comput Phys. 72, 243 (1987).

${ }^{10}$ J. Q. Dong, W. Horton, and W. Dorland, Phys. Plasmas 1, 3635 (1994).

${ }^{11}$ W. M. Tang and G. Rewoldt, Phys. Fluids B 5, 2451 (1993).

${ }^{12}$ F. Romanelli and F. Zonca, Phys. Fluids B 5, 4081 (1993).

${ }^{13}$ T. S. Hahm and W. M. Tang, private communication (1995).

${ }^{14}$ W. W. Lee and W. M. Tang, Phys. Fluids 31, 622 (1988).

${ }^{15}$ J. Connor, Nucl. Fusion 26, 193 (1986).

${ }^{16}$ T. H. Dupree, Phys. Fluids 11, 2680 (1968). 
${ }^{17}$ W. W. Lee, J. A. Krommes, C. Oberman, and R. A. Smith, Phys. Fluids 27, 2652 (1984). 


\section{Figures}

FIG. 1. Time evolution for the ITG instability for the three hydrogenic isotopes in terms of the electrostatic field energy (a) and the ion thermal diffusivity (b).

FIG. 2. The linear radial wavenumber $k_{r}$ spectra (a) and the time-averaged $k_{r}$ spectra in the nonlinear steady state (b).

FIG. 3. The time-averaged poloidal $k_{\theta}$ spectra (a) and toroidal $k_{\phi}$ spectra (b) in the nonlinear steady state.

FIG. 4. Spatially-averaged frequency spectra along the weak magnetic field side of the midplane for the three hydrogenic isotopes. 


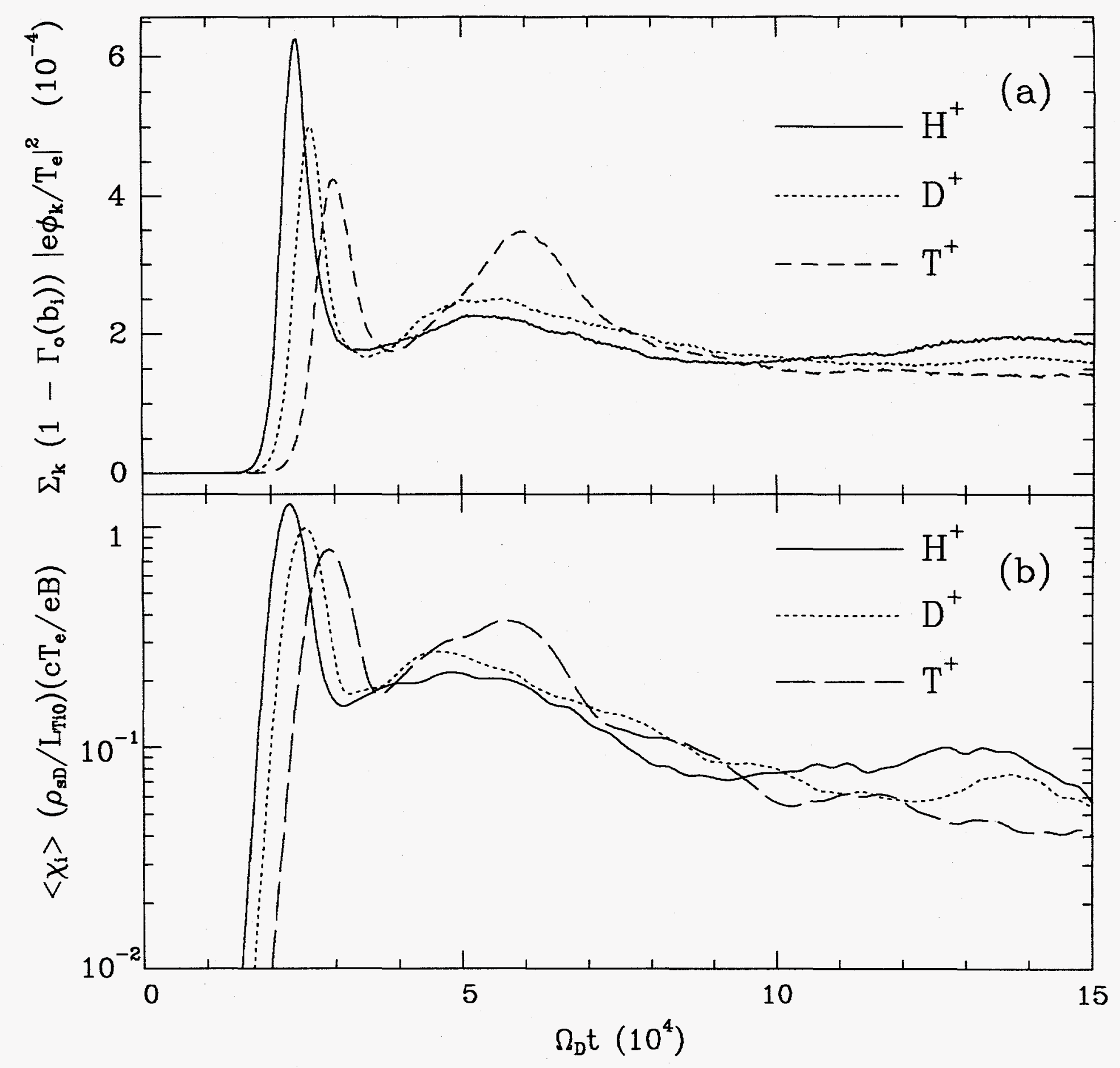

Fig. 1 


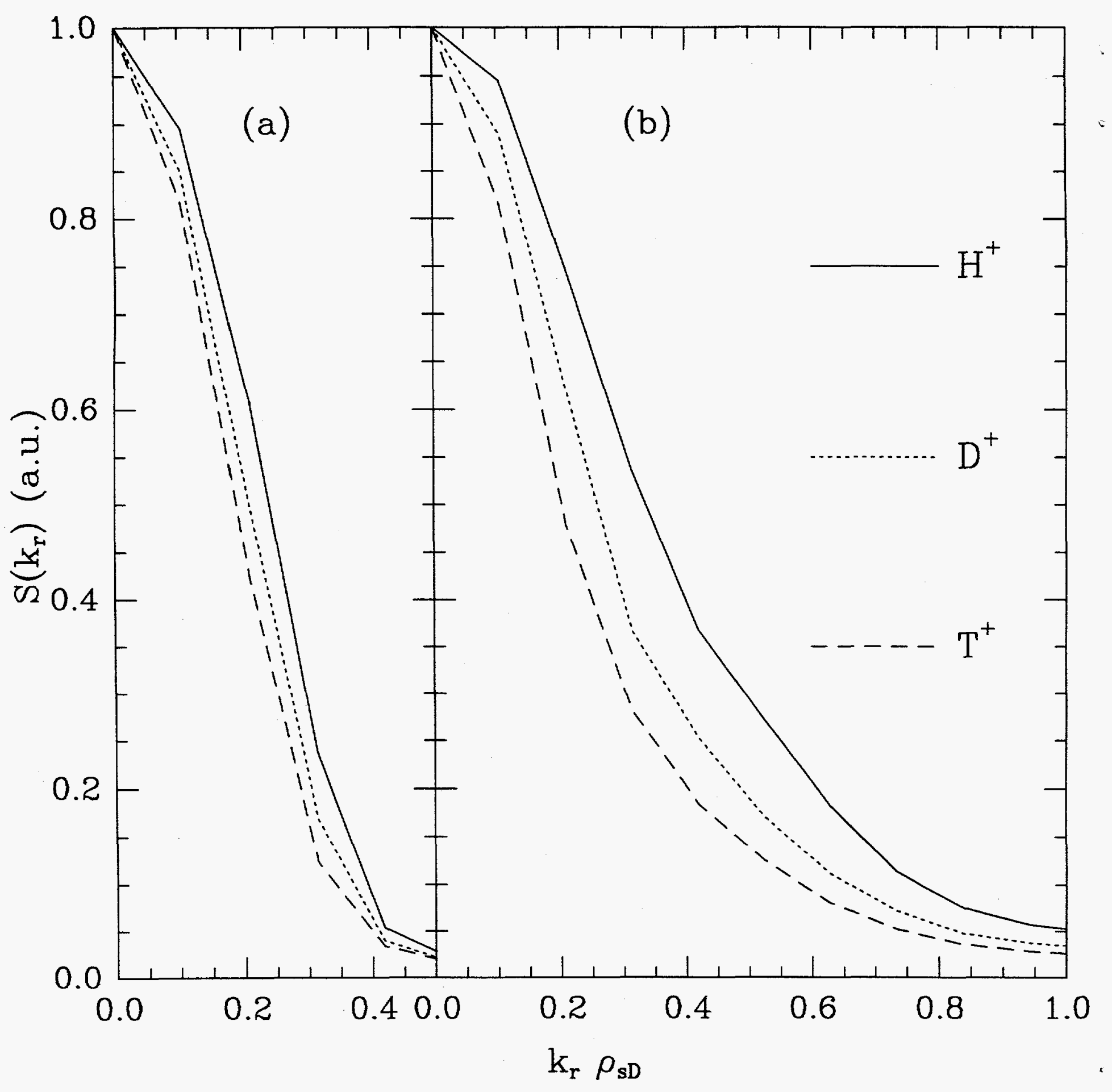

Fig. 2 

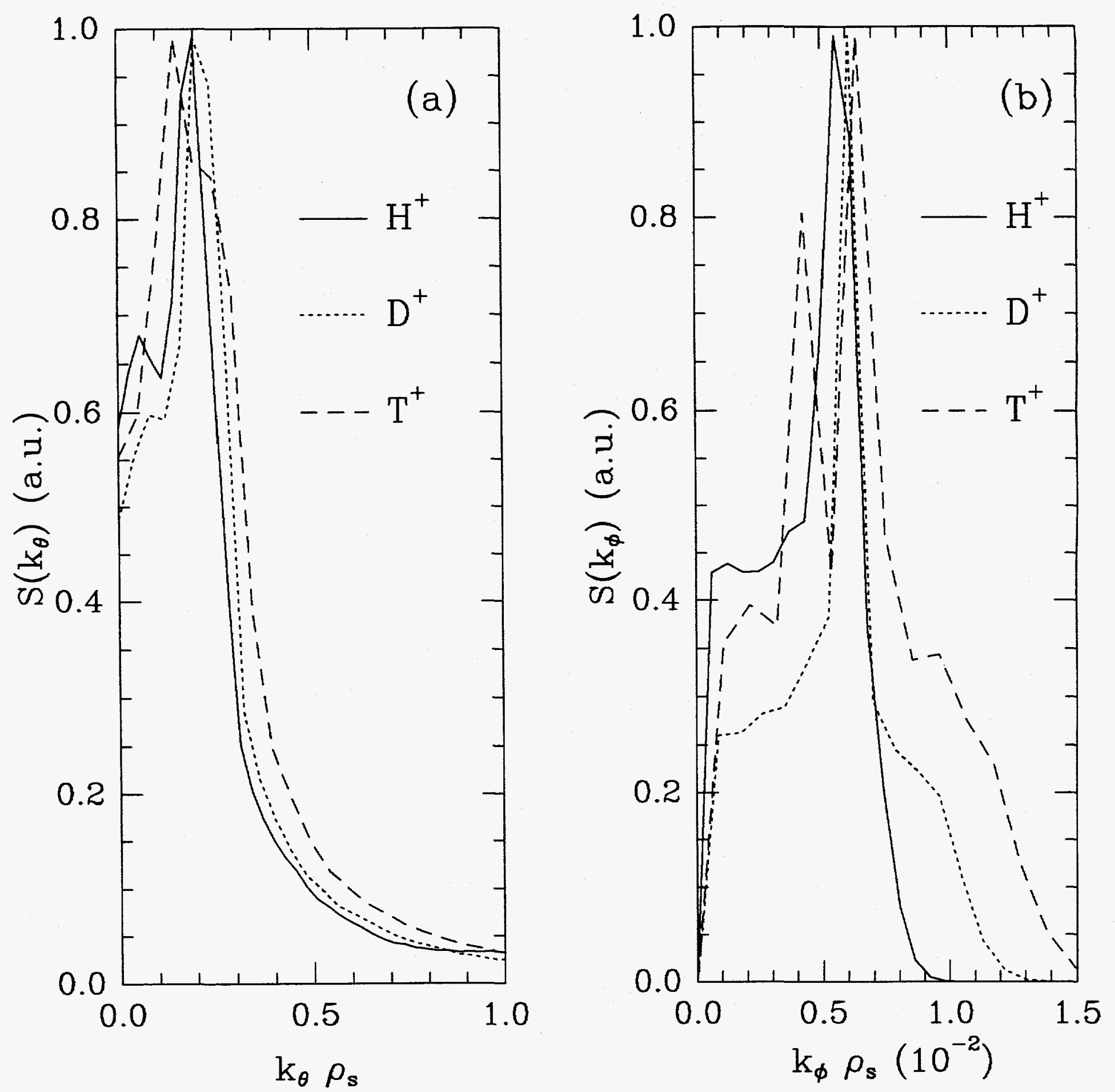

Fig. 3 


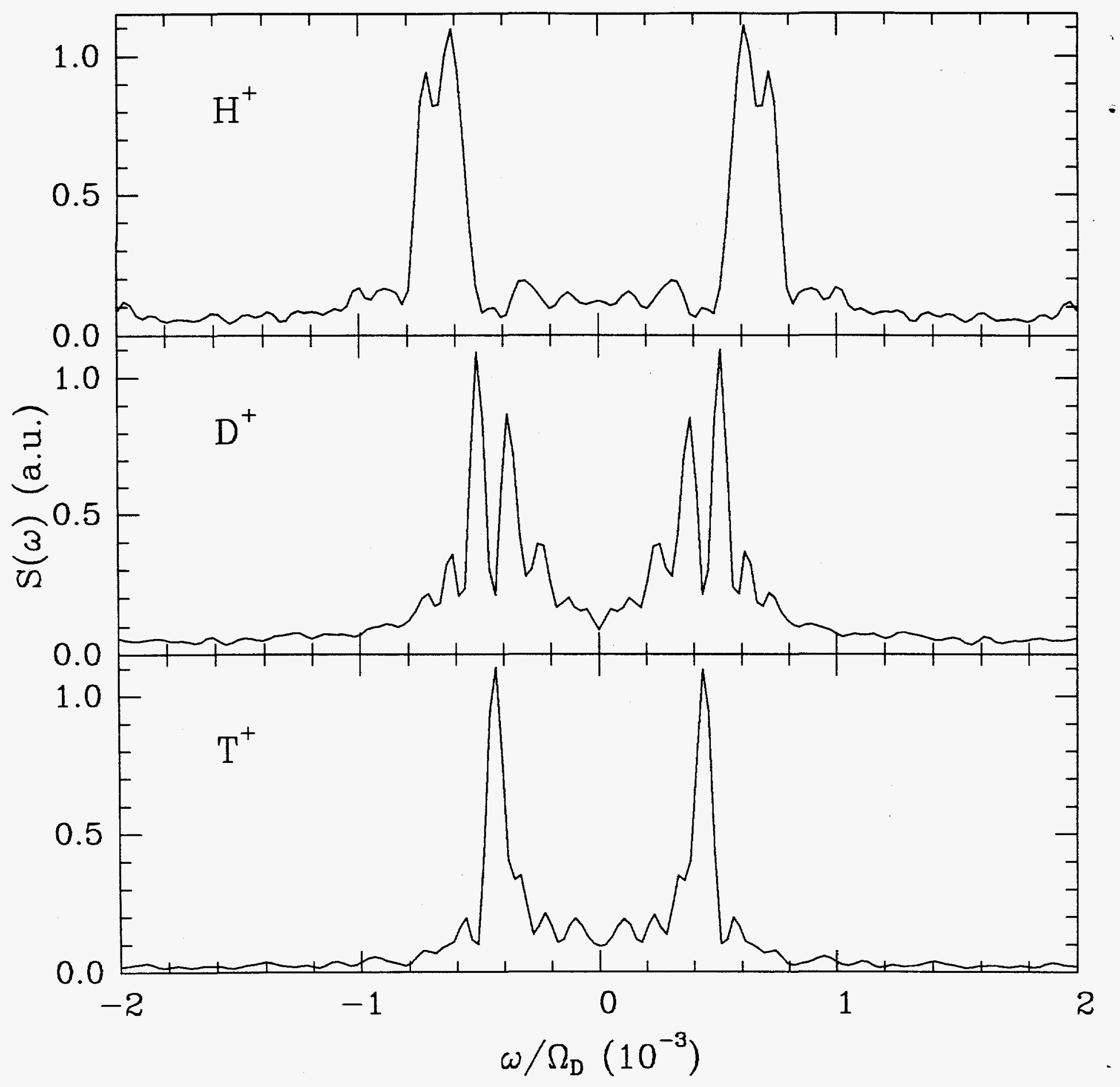

Fig. 4 
Dr. F. Paoloni, Univ, of Wollongong, AUSTRALIA

Prof. R.C. Cross, Univ. of Sydney, AUSTRALIA

Plasma Research Lab., Australian Nat. Univ., AUSTRALIA

Prof. I.R. Jones, Flinders Univ, AUSTRALIA

Prof. F. Cap, Inst for Theoretical Physics, AUSTRIA

Prof. M. Heindler, Institut für Theoretische Physik, AUSTRIA

Prof. M. Goossens, Astronomisch Instituut, BELGIUM

Ecole Royale Militaire, Lab. de Phy. Plasmas, BELGIUM

Commission-European, DG. XII-Fusion Prog., BELGIUM

Prof. R. Bouciqué, Rijksuniversiteit Gent, BELGIUM

Dr. P.H. Sakanaka, Instituto Fisica, BRAZIL

Prot. Dr. I.C. Nascimento, Instituto Fisica, Sao Paulo, BRAZIL Instituto Nacional De Pesquisas Espaciais-INPE, BRAZIL Documents Office, Atomic Energy of Canada Ltd., CANADA

Ms. M. Morin, CCFWTokamak de Varennes, CANADA

Dr. M.P. Bachynski, MPB Technologies, Inc., CANADA

Dr. H.M. Skarsgard, Univ, of Saskatchewan, CANADA

Prof. J. Teichmann, Univ. of Montreal, CANADA

Prof. S.R. Sreonivasan, Univ. of Calgary, CANADA

Prof. R. Marchand, INRS-Energie et Materiaux, CANADA

Dr. R. Bolton, Centre canadien de fusion magnétique, CANADA

Dr. C.R. James, Univ. of Alberta, CANADA

Dr. P. Lukác, Komenského Universzita, CZECHO-SLOVAKIA

The Librarian, Culham Laboratory, ENGLAND

Library, R61, Rutherford Appleton Laboratory, ENGLAND

Mrs. S.A. Hutchinson, JET Library, ENGLAND

Dr. S.C. Sharma, Univ. of South Pacific, FIJI ISLANDS

P. Mähönen, Univ. of Helsinki, FINLAND

Prof. M.N. Bussac, Ecole Polytechnique, FRANCE

C. Mouttet, Lab. de Physique des Milieux lonisés, FRANCE

J. Radet, CEN/CADARACHE - Bat 506, FRANCE

Prof. E. Economou, Univ. of Crete, GREECE

Ms. C. Rinni, Univ. of loannina, GREECE

Preprint Library, Hungarian Academy of Sa., HUNGARY

Dr. B. DasGupta, Saha Inst. of Nuclear Physics, INDIA

Dr. P. Kaw, Inst. for Plasma Research, INDIA

Dr. P. Rosenau, Israel Inst of Technology, ISRAEL

Librarian, Intemational Center for Theo Physics, ITALY

Miss C. De Palo, Associazione EURATOM-ENEA, ITALY

Dr. G. Grosso, Istituto di Fisica del Plasma, ITALY

Prof. G. Rostangni, Istituto Gas lonizzati Del Cnr, ITALY
Dr. H. Yamato, Toshiba Res \& Devel Center, JAPAN

Prof. I. Kawakami, Hiroshima Univ., JAPAN

Prof. K. Nishikawa, Hiroshima Univ., JAPAN

Librarian, Naka Fusion Research Establishment, JAERI, JAPAN

Director, Japan Atomic Energy Research Inst., JAPAN

Prof. S. Itoh, Kyushu Univ., JAPAN

Research Info. Ctr., National Instit. for Fusion Scienć, JAPAN

Prof. S. Tanaka, Kyoto Univ., JAPAN

Library, Kyoto Univ., JAPAN

Prof. N. Inoue, Univ. of Tokyo, JAPAN

Secretary, Plasma Section, Electrotectinical Lab., JAPAN

Dr. O. Mitarai, Kumamoto Inst. of Technology, JAPAN

Dr. G.S. Lee, Korea Basic Sci. Ctr., KOREA

J. Hyeon-Sook, Korea Atomic Energy Research Inst., KOREA

D.I. Choi, The Korea Adv. Inst. of Sa. \& Tech., KOREA

Leandro Melendez Lugo, Inst. Nac1. de Inves. Nud, MEXICO

Prof. B.S. Liley, Univ. of Waikato, NEW ZEALAND

Inst of Physics, Chinese Acad Sci PEOPLE'S REP. OF CHINA

Library, Inst. of Plasma Physics, PEOPLE'S REP. OF CHINA

Tsinghua Univ. Library, PEOPLE'S REPUBLIC OF CHINA

Z. Li, S.W. Inst Physics, PEOPLE'S REPUBLIC OF CHINA

Prof. J.A.C. Cabral, Instituto Superior Tecnico, PORTUGAL

Prof. M.A. Hellberg, Univ. of Natal, S. AFRICA

Prof. D.E. Kim, Pohang Inst. of Sci. \& Tech., SO. KOREA

Prof. C.I.E.M.A.T, Fusion Division Library, SPAIN

Dr. L. Stenflo, Univ. of UMEA, SWEDEN

Library, Royal Inst. of Technology, SWEDEN

Prof. $H$. Wilhelmson, Chalmers Univ. of Tech., SWEDEN

Centre Phys. Des Plasmas, Ecole Polytech, SWITZERLAND

Bibliotheek, Inst. Voor Plasma-Fysica, THE NETHERLANDS

Asst. Prof. Dr. S. Cakir, Middle East Tech. Univ., TURKEY

Dr. V.A. Glukhikh,Sci. Res. Inst. Electrophys.I Apparatus, USSR

Dr. D.D. Ryutov, Siberian Branch of Academy of Sci., USSR

Dr. G.A. Eliseev, I.V. Kurchatov Inst., USSR

Librarian, The Ukr.SSR Academy of Sciences, USSR

Dr. L.M. Kovrizhnykh, Inst. of General Physics, USSR

Kemforschungsanlage $\mathrm{GmbH}$, Zentralbibliothek, W. GERMANY

Bibliothek, Inst. Für Plasmaforschung, W. GERMANY

Prof. K. Schindler, Ruhr-Universitát Bochum, W. GERMANY

Dr. F. Wagner, (ASDEX), Max-Planck-Institut, W. GERMANY

Librarian, Max-Planck-Institut, W. GERMANY 